paper that has been accepted but not yet published violates the policies of many journals. In a few cases, and only by arrangement with the editor, preliminary release of data may be acceptable - for example, if there is a public health emergency.

\title{
Acceptable Secondary Publication
}

\author{
International Committee of Medical Journal Editors
}

Secondary publication in the same or another language, especially in other countries, is justifiable, and can be beneficial, provided all of the following conditions are met.

1. The authors have received approval from the editors of both journals; the editor concerned with secondary publication must have a photocopy, reprint, or manuscript of the primary version.

2. The priority of the primary publication is respected by a publication interval of at least one week (unless specifically negotiated otherwise by both editors).

3. The paper of secondary publication is intended for a different group of readers; an abbreviated version could be sufficient.

4. The secondary version faithfully reflects the data and interpretations of the primary version.

5. The footnote on the title page of the secondary version informs readers, peers, and documenting agencies that the paper has been published in whole or footnote might read: "this article is based on a study first reported in the [title of journal, with full reference]."
Permission for such secondary publication should be free of charge.

\section{Protection of patients' rights to privacy}

Patients have a right to privacy that should not be infringed without informed consent. Identifying information should not be published in written descriptions, photographs, and pedigrees unless the information is essential for scientific purposes and the patient (or parent or guardian) gives written informed consent for publication. Informed consent for this purpose requires that the patient be shown the manuscript to be published.

Identifying details should be omitted if they are not essential, but patient data should never be altered or falsified in an attempt to attain anonymity. Complete anonymity is difficult to achieve, and informed consent should be obtained if there is any doubt. For example, masking the eye region in photographs of patients is inadequate protection of anonymity.

The requirement for informed consent should be included in the journal's instructions for authors. When informed consent has been obtained it should be indicated in the published article.

The notes in this statement are excerpts from: International Committee of M edical Journal Editors. Uniform Requirements for Manuscripts Submitted to Biomedical Jornals. Ann Intern Med 1997 Jan 1;126 (1):36-47. Available on website: http:/ / www. acponline.org/ journals/ 01 jan97/ unifregr.htm. This article includes: issues to consider before submitting a manuscript, requirements for submission of manuscripts, sending the manuscript to the journal, and separate declarations. 